\title{
natureza da transição e tipo de capitalismo: notas sobre o fim da economia de comando na urss e a emergência de um capitalismo dirigido pelo estado*
}

\section{the nature of the transition and the type of capitalism: notes on the end of command economy in the ussr and the emergence of a state-led capitalism}

\author{
Eduardo da Motta e Albuquerque ${ }^{\star}$ \\ Centro de Desenvolvimento e Planejamento Regional, Faculdade de Ciências Econômicas, Uni- \\ versidade Federal de Minas Gerais, Belo Horizonte, Minas Gerais, Brasil
}

\section{RESUMO}

Este artigo avalia a variedade de capitalismo da Rússia contemporânea - periférica, liderada pelo Estado, oligárquica e com uma democracia limitada - , resultado da transição baseada em terapias de choque. A escolha do tipo de transição foi condicionada pela natureza da crise da economia de comando na década de 1980. Essa crise foi o resultado de contradições internas da economia de comando construída entre 1929 e 1953. Essa economia de comando gerou um limitado processo de catch up, industrializou a economia com grande custo humano, gerando uma economia relativamente atrasada com fortes

\begin{abstract}
This paper evaluates contemporary Russia's variety of capitalism. This variety of capitalism - peripheric, State-led, oligarchic and with managed democracy - resulted from a transition based on shock terapies. The choice of the type of transition was conditioned by the nature of the crisis of the command economy in the 1980s. This crisis was a result of inner contradictions of the command economy built between 1929 and 1953. This command economy generated a limited catch up process, industrialized the economy with great human cost, delivering a relatively backward economy with strong
\end{abstract}

* Agradeço o apoio do CNPq (Processos n. 302.857/2015-0 e n. 401.054/2016-0). As turmas das disciplinas Industrializações Comparadas, Sistemas Econômicos Comparados e História e Interpretações da Sociedade Contemporânea ministradas na FACE-UFMG, entre 2005 e 2016, contribuíram para o desenvolvimento do roteiro aqui apresentado. Agradeço os comentários de dois pareceristas anônimos da revista História Econômica \& História de Empresas. Os erros são responsabilidade exclusiva do autor.

Submetido: 6 de março de 2017; aceito: 2 de janeiro de 2018.

$\star \star$ Professor titular do Centro de Desenvolvimento e Planejamento Regional (CEDEPLAR) e da Faculdade de Ciências Econômicas da Universidade Federal de Minas Gerais. Doutor em Economia pela Universidade Federal do Rio de Janeiro. E-mail: albuquer@cedeplar.ufmg.br 
capacidades militares. Este artigo analisa quatro questões: a natureza da economia entre 1929 e 1985, o ponto crítico relativo ao fim da URSS no final dos anos 1980, o tipo de transição e as principais características da variedade de capitalismo que emergiu como uma consequência desses processos.

Palavras-chave: Rússia. Economia de comando. Tipos de transição. Variedades de capitalismo. military capabilities. This paper reviews four issues: the nature of the economic system between 1929 and 1985, the critical point that ended the command economy in late 1980s, the type of transition and the main features of the variety of capitalism that emerged as a consequence of those processes.

Keywords: Russia. Command economy. Types of transition. Varieties of capitalism.

\section{Introdução}

O processo de transição de uma economia de comando para uma economia de mercado na URSS terminou com o surgimento de uma nova variedade de capitalismo. No processo de fim da economia de comando, encontra-se a dissolução da URSS, por isso este texto busca avaliar o tipo de capitalismo que emerge na Rússia, ao final do processo de transição. A sugestão deste texto é considerar que o tipo de capitalismo em implantação na Rússia é derivado da natureza da transição imposta à economia de comando, processo iniciado com as reformas do período Gorbachev (1985-1991).

O conjunto do processo histórico da URSS (Nove, 1992) traz inúmeras lições para a teoria econômica. Entre 1913 e 2016 a Rússia passou por pelo menos sete diferentes regimes econômicos. Apenas entre 1913 e 1928 a Rússia (após 1922 a URSS) experimentou quatro diferentes regimes econômicos. Há controvérsia se o sistema econômico que emerge da bancarrota da economia de comando já passa por uma transformação importante a partir do início do século XXI.

Para discutir a natureza do sistema econômico atual, é necessário, portanto, investigar o processo de transição em curso desde 1985. As polêmicas em torno desse processo não são pequenas. Este texto está organizado em quatro seções que acompanham quatro questões. Em primeiro lugar, o ponto de partida das reformas é controverso: Qual sistema econômico existia na URSS? Em segundo lugar, o momento da transição é disputado: Quando a economia de comando foi desmantelada? Em terceiro lugar, o processo de transição que teve lugar na URSS é de um tipo muito específico: A terapia de choque não era a 
única alternativa disponível? Adicionalmente, o final da economia de comando em sua forma específica de transição a uma economia de mercado contribui para a avaliação da natureza da economia de comando que emergiu sob Stalin. Finalmente, a caracterização do resultado do processo está em aberto: Capitalismo de mercado, de Estado, patrimonial, normal e/ou periférico?

\section{A natureza da economia antes da transição}

A vitória política de Stalin em 1928-1929 abre uma nova fase na história econômica da URSS, com o estabelecimento de um regime totalitário (Trotsky, 1937, p. 127; Hilferding, 1940; Rosdolsky, 1959, p. 214; Arendt, 1968, p. xxiii) $)^{1}$, no qual o terror é uma arma na construção do arcabouço institucional político desse regime (Tucker, 1992, cap. 8, 12, 15, 16). Como emblema das consequências dessa estrutura política sobre o processo de industrialização, Davies (1998, p. 49) apresenta estatísticas do total de prisioneiros do "sistema de trabalho forçado": 2,51 milhões em 1933 e 5,49 milhões em 1953².

Com a vitória política de Stalin em 1928-1929, consolidou-se o bloco central da definição da economia de comando: o "poder monolítico" do PC sobre a economia e a sociedade soviéticas (Kornai, 1992, p. 360-361) é o primeiro bloco da "cadeia principal de causalidade" definido por Kornai ${ }^{3}$. Esse "poder monolítico" comanda uma cadeia de

1 A articulação entre eventos políticos posteriores a 1917 e a emergência do totalitarismo stalinista é objeto de vastas controvérsias - para uma sistematização de diferentes posições sobre o tema, ver Tucker (1977). Talvez o mais precoce alerta sobre esses problemas está na insistência de Riazanov, Kamenev e Sokolnikov sobre a necessidade de preservar a aliança entre os bolcheviques, os socialistas-revolucionários e os mencheviques após novembro de 1917 (Deutscher, 1954, p. 354-359). A crítica de Rosa Luxemburgo (1918) ao fechamento da Assembleia Constituinte é outro alerta profético. Finalmente, Lewin (1974, p. 98) destaca a articulação entre as práticas do período do "comunismo de guerra" e as medidas iniciais da montagem do que veio a ser o modelo stalinista.

2 Segundo um levantamento realizado em 2006, pelo menos $27 \%$ da população da Rússia é composta por descendentes de vítimas de Stalin (Cohen, 2011, p. 59).

3 As características básicas da economia de comando e da emergência do modelo stalinista podem ser encontradas em Rosdolsky (1959), Lewin (1974), Nove (1992) e Kornai (1992). 
decisões que começa nas decisões administrativas e burocráticas do planejamento central e desce para os níveis de gerência subordinados, até chegar às unidades produtivas.

A partir dessa definição política, estabeleceu-se entre 1929 e 1941 o contorno do que Oskar Lange (1957, p. 123) denominou "uma economia de guerra sui generis" (Nove, 1992; Tucker, 1992). A um custo humano e social enorme (Rosdolsky, 1959; Tucker, 1992; Conquest, 1986; Lewin, 1968; Nove, 1992; Davies, 1998), essa economia de comando foi capaz de industrializar a URSS. Porém, a natureza da estrutura industrial legada pelo processo de industrialização e coletivização forçada envolveu um considerável nível de atraso tecnológico (Hanson; Pavitt, 1987, p. 26): quando a industrialização se completa, ela já estava superada tecnologicamente, dada a emergência de um conjunto de novas tecnologias no início da quarta onda longa desde o final da Segunda Guerra Mundial (Freeman; Louçã, 2001). Evidências da percepção interna à URSS desse atraso tecnológico podem ser encontradas em 1958 - auge do período intitulado por Davies (1998, p. 67) como a era de ouro do desenvolvimento soviético (1950-1965) - com o esquema de Khruschev para o desenvolvimento da indústria química - tratava-se de um atraso de pelo menos duas décadas (Hanson, 2003, p. 62).

As características principais desse sistema econômico foram descritas por Nove (1992, p. 267-271) e Kornai (1992, p. 360-365) ${ }^{4}$. As implicações desse sistema econômico para a dinâmica inovativa foram discutidas por Hanson e Pavitt (1987) - Lewin (1974, p. 117) avalia que incorporada na estrutura do modelo stalinista está uma "fobia de inovações". A limitação da capacidade inovativa da economia de comando tem raízes estruturais, que pode ser sintetizada na dependência da inovação na economia de comando em relação à construção de novas unidades produtivas (Hanson; Pavitt, 1987, p. 32). Essa dependência decorre da natureza extensiva do crescimento econômico na economia de comando (Kornai, 1992, p. 183), da visão de Stalin sobre a importância da construção do maior número possível de fábricas (Lewin,

4 O período entre 1928 e 1953 (stalinismo sob Stalin) pode ser dividido em diversas fases - Davies (1998, p. 43-72), por exemplo, divide-o em quatro fases: industrialização pré-guerra (1928-1941), Segunda Guerra Mundial, recuperação pós-guerra (1945-1950) e expansão do pós-guerra (iniciada em 1950). Já o período de “industrialização pré-guerra" é dividido por Davies em cinco subfases. 
1974, p. 103), do isolamento entre as instituições de pesquisa e as unidades produtivas (Hanson; Pavit, 1987, p. 24), do impacto microeconômico do soft budget constraint sobre a inovação nas empresas (Kornai, 1992, p. 140-145) e da relação entre economia de escassez e de "mercado de vendedores" com a ausência de incentivos para a inovação (Kornai, 1992, p. 229-234, 245-252).

Desse arranjo estrutural resulta um padrão de industrialização capaz apenas de um catch up incompleto - segundo os dados de Maddison (2010), a URSS nunca ultrapassou o limite de 38\% do PIB per capita dos Estados Unidos (Gráfico 1), o que indicaria um país vítima da "armadilha da renda média" "Evidente que há uma relação entre a natureza da industrialização e os limites no processo de catch up: a característica do planejamento burocrático derivado do monopólio do poder pelo PC da URSS, os problemas derivados dessa administração burocrática, os bloqueios que esse sistema impõe à dinâmica inovativa (uma microeconomia da estagnação e da inércia) e, portanto, à capacidade de implementar um processo de catch up completo - o caso do Japão, conforme o Gráfico $1^{7}$.

A economia de comando (ou o "modelo stalinista") ${ }^{8}$, constituída entre 1928 e 1953, será objeto de diversas tentativas de reformas, econômicas e políticas, até 1991 .

5 Uma avaliação da natureza da economia que emerge após a vitória política de Stalin - assim como uma discussão dos diferentes regimes econômicos que existiram entre 1917 e 1929 - está sintetizada em trabalho anterior (Albuquerque, 2005).

6 A questão do cálculo dos indicadores econômicos no caso da URSS não é simples. Nove (1992, p. 430-438) discute problemas nos cálculos de taxas de crescimento na URSS. Davies (1998, p. 42) apresenta uma tabela comparando os diversos valores do Produto Nacional Bruto da URSS entre 1928 e 1960. Para localizar os cálculos de Maddison (2010), com um índice igual a 100 em 1928, temos três diferentes resultados em 1965:1) para os dados oficiais, o índice seria 3.063;2) para os cálculos da CIA, seria 517; 3) para Maddison, seria 462.

7 Para uma apresentação do catch up japonês, ver Ohkawa e Kohama (1989).

8 Os debates sobre a natureza do sistema econômico da URSS são amplos. Linden (2007) revisita a enorme controvérsia entre autores considerados marxistas - além da sistematização das posições, Linden organiza a sua revisão acompanhando as mudanças históricas na URSS, uma contribuição para entender como o processo histórico proporcionava novas questões para a interpretação teórica. Para uma outra revisão abrangente, ver King e Szelényi (2005). 
Gráfico 1 - Hiato do PIB per capita da URSS (e ex-URSS), do Japão e do Brasil em relação ao PIB per capita dos Estados Unidos (1990 International Geary-Khamis dollars), 1913-2008

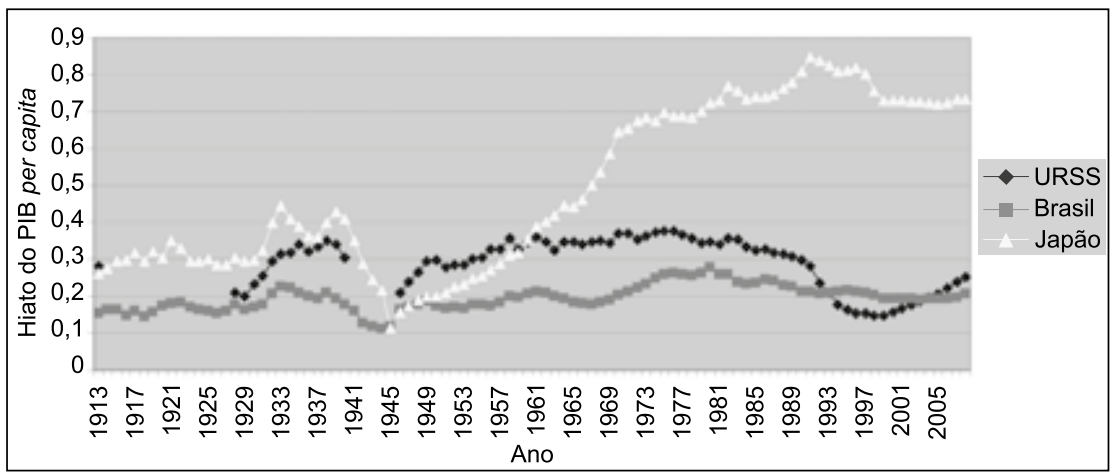

Fonte: Maddison (2010), elaboração própria.

No campo político, desde a morte de Stalin importantes mudanças ocorrerão. Hanna Arendt (1968, p. xxv, xxxiv-xl) avalia que a natureza totalitária do regime se encerra com a morte de Stalin. Mesmo parciais, as medidas de liberação de prisioneiros dos campos de trabalho e anistias parciais sob Khruschev têm enorme repercussão sobre a vida e a sociedade soviéticas, no presente e no futuro (Cohen, 2011, cap. 2). A retomada de políticas conservadoras por Brezhenev não foram suficientes para reverter o regime às suas características políticas vigentes sob Stalin - uma das características da era Brezhenev é a "rotinização do sistema socioeconômico stalinista" (Hanson, 2006, p. 303), com a estabilização da burocracia - uma "era de ouro da nomeklatura", segundo Cohen (2011, p. 72).

No campo econômico, há consequências derivadas do final do processo de industrialização ${ }^{9}$. Como ressalta Rosdolsky (1959, p. 227), uma vez completada a industrialização, estaria demolida a base histórica do fenômeno do stalinismo, pois a URSS poderia entrar em um processo de acumulação normal. Certamente essa é uma mudança crucial, que Rosdolsky (1959, p. 227-228) discute como base para esperança de

$9 \quad$ Em 1928 o produto da indústria correspondia a menos do que a metade do produto da agricultura. Em 1937 a indústria ultrapassa a agricultura e em 1955 o produto da indústria chega a aproximadamente o dobro do produto da agricultura (Davies, 1998, p. 82). 
renascimento de uma democracia socialista na URSS. A economia de comando estabelecida sob Stalin, com suas instituições consolidadas - e aqui o contexto geopolítico da Guerra Fria pode ser lido como um elemento de estabilização no cenário internacional, consolidando a URSS como um dos polos de um mundo bipolar-, conhecerá importantes tentativas de reforma. Porém, nenhuma tentativa focalizou a transição da economia recém-industrializada para um novo estágio, em contraste com o caso do Japão, um exemplo estilizado de flexibilidade na definição de novas políticas industriais, na medida em que fases se completavam (Ohkawa; Kohama, 1989): a incapacidade de superar a fase de crescimento econômico "extensivo" persiste até o final do período Gorbachev $^{10}$.

Com Khruschev inicialmente, através da instalação de "conselhos econômicos regionais" (Nove, 1992, p. 351), descentralização revertida por Brezhenev, que por sua vez implementa as "reformas de Kossygin", encerradas com a reação diante das mudanças da "Primavera de Praga". Brezhenev implementa, de acordo com Hanson (2006, p. 301-305), um novo "contrato social" entre o partido e a população soviética, envolvendo cinco aspectos: estabilidade no emprego, preços baixos para produtos básicos, tolerância com a economia informal, uma forma limitada de ascensão social e esferas controladas de expressão para populações não russas ${ }^{11}$.

Durante o período Brezhenev, cresceu a dependência da economia em relação à exploração de petróleo e a outros recursos naturais - descobertas do período Khruschev (Nove, 1992, p. 362) -, cuja produção se ampliou consideravelmente no final dos anos 1960. Essa expansão foi beneficiada com a elevação dos preços de petróleo em meados dos anos 1970, transformando o petróleo no mais importante produto de exportação da URSS para o Ocidente (Nove, 1992, p. 391). Essa dependência em relação aos recursos naturais - característica posterior aos anos 1970 - deve ser acrescentada a um diagnóstico da situação estrutural da eco-

10 Seria interessante uma comparação mais sistemática entre o planejamento das políticas industriais no Japão (Ohkawa; Kohama, 1989) e o caráter limitado, improvisado e sem clara visão estratégico do "planejamento" na URSS (Gregory; Harrison, 2005): um catch up completo no primeiro caso, um catch up incompleto no segundo.

11 As características estruturais apresentadas por Kornai (1992) parecem ser uma descrição da economia soviética nesse período. 
nomia soviética: além do catch up incompleto (retratado no Gráfico 1), ela torna-se crescentemente dependente da exploração de recursos naturais. Ou seja, em vez de avançar em direção a novos setores de maior conteúdo tecnológico, especialmente no período Brezhenev, a economia move-se em direção da produção de recursos naturais ${ }^{12}$.

Em termos da natureza da economia soviética, as reformas tentadas não tocaram no ponto definidor da natureza da economia de comando: o monopólio do partido único sobre o planejamento econômico e a vida política da URSS. Nesse sentido, apesar das tentativas de reforma, da industrialização e de mudanças estruturais importantes como o peso da produção de recursos naturais, a caracterização da economia soviética não mudou: economia de comando. A novidade é a intensidade da crise do planejamento e da URSS como um todo: Nove (1992, p. 387) termina a discussão do período Brezhenev com uma seção intitulada "uma situação pré-crise".

Como resumir a situação da economia que entrará na era das reformas liderada por Gorbachev? Em 1985 a URSS é praticamente alcançada pelo Japão em termos de PIB - em 1957 o PIB da URSS era quase o triplo do PIB do Japão (Maddison, 2001). Ao perder a posição de segunda economia do mundo, a URSS era uma economia tecnologicamente atrasada - produtora de aço e recursos naturais em um momento no qual a revolução das TICs emite os seus primeiros sinais no Ocidente -,importadora de bens de capital e produtos agrícolas, com um setor militar razoavelmente estruturado, ilhas de eficiência em setores relacionados à defesa e à corrida espacial, uma capacidade científica importante, mas desarticulada do sistema produtivo, uma estrutura de planejamento econômico que, desde o período Khruschev, demonstrava ser incapaz de responder às demandas de uma economia mais complexa, um sistema econômico que perdia dinamismo em função dos limites crescentes da coerção dos tempos de Stalin em impor disciplina sobre os trabalhadores (custos de monitoramento crescentes), uma economia com uma dinâmica inovativa ainda mais limitada graças ao esgotamento da principal fonte de inovação - a construção de novas fábricas -, sem a sua substituição por outra fonte.

12 Segundo os dados de Maddison (2001) apresentados no Gráfico 1, é nesse período que o PIB per capita da URSS mais se aproxima do PIB per capita dos Estados Unidos: $\mathrm{y}=0,376$ em 1975 . 
Nesse contexto, a queda dos preços do petróleo tem um efeito importante sobre a economia da URSS (Nove, 1992, p, 392; Hanson, 2006, p. 310): acumulam-se sinais de crise.

\section{Ponto crítico: o fim da economia de comando}

Após o encerramento de três governos entre 1982 e 1985 (Brezhenev, Andropov e Chernenko), a era Gorbachev se inicia em março de 1985, um período de reformas profundas no sistema econômico e político soviético.

Dada a profundidade da crise no conjunto do sistema da economia de comando, Gorbachev representou uma aposta em reformas abrangentes. O impacto inicial das reformas propostas por Gorbachev são tais, que abrem uma nova fase nos debates entre plano e mercado no pensamento econômico ${ }^{13}$.

Três linhas de atuação devem ser destacadas no plano de reformas de Gorbachev: em primeiro lugar, a decisão de terminar com a Guerra Fria; em segundo lugar, as reformas políticas (Glasnost) e, em terceiro lugar, as reformas econômicas (Perestroika). Essas três linhas de reformas interagem e sua interação define a dinâmica específica desse período (entre 1985 e 1991): o desmoronamento da economia de comando é consequência das medidas tomadas no front externo e das reformas políticas.

As iniciativas políticas de Gorbachev levam ao fim da Guerra Fria (Cohen, 2011, p. 156-157). Segundo o historiador Eric Hobsbawm, "para fins práticos, a Guerra Fria terminou nas duas conferências de cúpula de Reykjavik (1986) e Washington (1987)" (Hobsbawm, 1994, p. 246). Esse fim de um cenário geopolítico funcional para a sobrevivência da URSS desmontou um elemento-chave constitutivo da economia de comando constituída sob Stalin: a ameaça de guerra. A importância dessa ameaça (real ou fantasmagórica) - e da ameaça de um cerco à URSS - na forma específica e concreta que a montagem da economia

13 O debate entre Nove (1983), Mandel (1986) e Elson (1988), nas páginas da New Left Review, é uma mostra desse impacto. Uma nova rodada do debate entre plano e mercado se inicia. 
de comando ocorreu está descrita por Tucker (1992, em especial cap. 3, 4): uma "industrialização orientada para a guerra" (Tucker, 1992, p. 50) resulta em uma "economia de guerra sui generis" (Lange, 1957, p. 123). O fim da Guerra Fria não pode deixar de ter um efeito devastador sobre essa lógica que está na base da economia de comando.

Relacionada a essa dinâmica, em novembro de 1986, Gorbachev deixa claro que, em relação à Europa Oriental, não mais haveria intervenções militares (Brown, 2006, p. 336) ${ }^{14}$. Essa enorme mudança estrutural alimenta um processo que termina com a queda do Muro de Berlin, em novembro de 1989. As mudanças no Leste Europeu por sua vez afetam a dinâmica na URSS de diversas formas. Entre os eventos decisivos que têm lugar na Europa Oriental nesse período, destaca-se a eleição polonesa de 4 de junho de 1989, que tem como resultado a constituição do primeiro governo sem um PC na Europa Oriental. Esse governo implementará um conjunto de reformas - um "big bang" na Polônia, um salto em direção a uma economia de mercado (Sachs, 2012) -, que posteriormente impactaria o processo na Rússia, influindo na escolha do tipo de transição a ser implementado lá.

As mudanças políticas são profundas. Há aqui uma dinâmica decisiva para o tema desta seção, na medida em que as "reformas políticas" levaram a uma "transformação sistêmica" (Brown, 2006, p. 325). No plano das reformas econômicas, Nove (1992, cap. 14) avalia o trânsito entre "reforma e desastre", e Hanson (2003, cap. 7) utiliza o termo "Catastroika". O importante aqui é ressaltar a integração das três dinâmicas, pois a dinâmica especificamente econômica nesse processo é determinada pelo conjunto do processo político - aliás, como foi o processo de construção política da economia de comando sob Stalin. Como Cohen ressalta, "o processo de democratização foi mais longe do que as reformas econômicas de Gorbachev" (Cohen, 2011, p. 77).

As reformas econômicas começaram já no início do governo Gorbachev. Nove (1992, p. 394) descreve essa "primeira onda de reformas", mencionando que inicialmente parecia uma reedição das reformas de Kossygin. A necessidade da reforma era clara, mas não havia clareza em

14 Essa proclamação de Gorbachev alimenta a retomada de processos prévios ocorridos na Alemanha (1953), Hungria (1956), Polônia (1982), sempre contidos com a chegada das tropas soviéticas. Rosdolsky (1959, p. 226) comenta que em 1956 as massas na Hungria demandavam uma democracia burguesa e capitalista. 
que direção realizá-la. Hanson (2003, p. 192) avalia o caráter de "tentativa e erro" desse processo: não havia um plano para as reformas. Cohen $(2011$, p. 70-75, 100) descreve as diversas facções no interior do PC da URSS e as disputas entre elas, desde a ascensão e queda de Khruschev, profundamente intensificada ao longo dos processos de Glasnost e Perestroika. Nesse sentido, o próprio Gorbachev seria um enigma, com as suas mudanças de posição depois de 1985. Segundo Cohen (2011, p. 73), o programa de Gorbachev no final dos anos 1980 teria similaridade com os partidos sociais democratas europeus. Poderia ser acrescentado que apenas aí se esboça de forma mais acabada um projeto de alternativa à economia de comando.

Nesse processo de tentativa e erro confuso (Hanson, 2003, p. 194), três medidas econômicas destacam-se entre as reformas tentadas pela equipe de Gorbachev, antes de 1989-1990. Em novembro de 1986 foi decretada a "Lei sobre as Atividades Econômicas Individuais" (Brown, 2006, p. 333) para setores como oficinas de consertos, serviços de táxi etc. Em 1987 veio uma nova "Lei sobre Empresas Estatais" (Nove, 1992, p. 401; Brown, 2006, p. 333), uma tentativa de descentralização econômica: mais autoridade para o nível da empresa, em especial para os gerentes das empresas. Essa lei abriu espaço para que, nos anos finais da URSS e nos iniciais após a sua bancarrota, gerentes de fábricas aproveitassem o fortalecimento de seus direitos de propriedade para "converter o seu controle de empresas industriais em propriedade" (Brown, 2006, p. 333). Esse processo será posteriormente conhecido como a fase de "privatização espontânea", a primeira das ondas de privatização na transição para o mercado (Augustynowicz, 2014, p. 137). Em 1988 é introduzida a "Lei das Cooperativas", que não prescrevia um número máximo de trabalhadores que poderiam ser empregados em uma cooperativa. De acordo com Brown (2006, p. 334), essa lei na prática tornou indistinguíveis cooperativas e empresas privadas. Essas mudanças combinadas representaram uma mudança inicial na estrutura da economia soviética, com empresas privadas responsáveis por cerca de $5 \%$ ou $6 \%$ do PIB em 1990 (Cohen, 2011, p. 105).

Em 1989 há um evento importante: o PIB da China ultrapassa o PIB da URSS (Maddison, 2001), que se torna o quarto PIB do mundo. O Gráfico 1 indica que as reformas não revertem a dinâmica de ampliação do hiato em relação à economia dos Estados Unidos. A situação de impasse econômico vai se desenhando com mais clareza na URSS. 
Enquanto isso, a dinâmica das reformas políticas prossegue, com a Glasnost impondo avanços irreversíveis. Marcos importantes nesse processo são as eleições parlamentares de 1989 e 1990, vistas como "viradas históricas” (Cohen, 2011, p. 76). São eleições que na prática quebram o monopólio do PC sobre a vida política da URSS. Essas transformações culminam no fim do monopólio do poder pelo PC (Nove, 1992, p. 410), removido legalmente da Constituição da URSS em março de 1990 (Brown, 2006, p. 328-329).

Esse o ponto crítico do processo de fim da economia de comando, pois o monopólio do partido único era o primeiro bloco da estrutura política que impulsionava a estrutura burocrático-administrativa da economia de comando (Kornai, 1992, p. 360-361). Uma vez removido esse primeiro bloco, a ruína do conjunto do sistema começa (Cohen, 2011, p. 76-77) ${ }^{15}$. Nos termos de Kornai, a transição para o capitalismo pode começar por outros blocos de sua "cadeia de causalidade", mas apenas se completa quando "a mudança necessária ocorre no bloco 1" (Kornai, 2000, p. 29, 33). No caso da URSS, o bloco 1 (monopólio do poder pelo partido único) foi transformado antes das mudanças nos blocos 2 (propriedade estatal continuou preponderante) e 3 (coordenação burocrática da economia mantida, embora em crise profunda).

O diagnóstico de Brown indica a ultrapassagem de um ponto crítico: a economia da URSS “já não era uma economia de comando, mas ainda não era uma economia de mercado” (Brown, 2006, p. 335) ${ }^{16}$.

É nesse contexto que em 1990 Yeltsin e Gorbachev organizam um grupo liderado por Shatalin e Iavlinskii, que prepara um documento com propostas para uma transição para uma economia de mercado Plano dos 500 dias, uma transição para uma economia de mercado em 500 dias (Brown, 2006, p. 334), documento apresentado para Gorbachev em agosto de 1990 (Grigoryev, 2016, p. 79). Na preparação desse Plano dos 500 dias, os efeitos de mudanças em curso no Leste Europeu começam a ser sentidos na Rússia e na URSS: Iavlinskii acompanhou as reformas na Polônia e no início de 1990 encontra-se com Jeffrey

15 Há uma discussão sobre a reformabilidade da economia de comando, que foge ao escopo desta seção. Kornai (1992, p. 570-571) sustenta que o sistema seria irreformável, enquanto Cohen (2011, cap. 4) defende o oposto.

16 Aslund avalia que apenas em "janeiro de 1992 a transição para uma economia de mercado começou na Rússia” (Aslund, 2014, p. 92). 
Sachs, então assessorando as reformas no governo do Solidariedade (Sachs, 2012) ${ }^{17}$.

$\mathrm{Na}$ esfera política, em 12 de junho de 1991 Boris Yeltsin é eleito presidente da Rússia; em 8 de dezembro de 1991 é assinado o documento de Belovezh (entre os presidentes da Rússia, da Ucrânia e da Bielorrússia), decretando o fim da URSS, final reconhecido publicamente pelo presidente da URSS - Gorbachev - em 25 de dezembro de 1991 (Brown, 2006, p. 349). O Estado russo está em condições de implementar o processo de reestruturação da economia, ao substituir o bloco 1 da economia de comando pelo bloco 1 de uma economia capitalista: um poder político favorável à propriedade privada e ao mercado (Kornai, 2000, p. 29).

Um detalhe importante: em 1991, segundo os dados de Maddison (2010), o PIB per capita da URSS é 28,1\% do PIB per capita dos Estados Unidos - exatamente o hiato existente em 1913 (ver Gráfico 1) ${ }^{18}$.

\section{Terapia de choque como método de transição}

Há diversas tipologias de transições disponíveis na literatura. Kornai (2000) sugere três tipos de transição, do que ele chama de socialismo para o capitalismo:

1) golpes militares anticomunistas (deposição de Bela Kun na Hungria, o golpe de Pinochet);

2) "revoluções de veludo", no qual um regime democrático emerge dos escombros do regime político anterior (Leste Europeu);

3) transformação interna do PC para uma posição pró-mercado (China,Vietnã).

Outra tipologia é apresentada por Naughton (1995):

17 Para a compreensão histórica do conjunto da transição, há hoje alguns textos de economistas que atuaram como consultores no processo que podem ser lidos como narrativas de participantes do processo de reforma. Exemplos são Sachs (2012), Aslund (2014) e Grigoryev (2016, p. 79).

18 Esse dado é importante para uma avaliação geral do conjunto da experiência da URSS, como Nove (1992, p. 430-438) destaca. 
1) reformas racionalizantes da Europa Oriental nos anos 1960;

2) reformas tipo "big bang" (Leste Europeu);

3) abordagem "pista dupla" (dual track) (China).

Finalmente, King e Szelényi (2005) diferenciam os atores mais importantes (empresas multinacionais, burocracia ou novas empresas) na transição para definir novas variedades de capitalismo:

1) reforma desde fora (Hungria, Polônia, República Checa);

2) reforma desde cima (Rússia);

3) reforma desde baixo (China).

Por essas tipologias, a transição na Rússia pode ser definida como "substituição de regime político" (tipo 2 de Kornai), reformas tipo "big bang" (tipo 2 de Naughton) e "reforma desde cima" (tipo 2 de King e Szelényi).

A natureza da transição na URSS foi definida politicamente. Em primeiro lugar, a dinâmica é consequência de longo prazo dos problemas inerentes ao modelo stalinista. Por isso, talvez não seja possível demarcar como sugere Grigoryev tão claramente os efeitos da transição e da economia de comando stalinista. Para ele, "em termos da teoria da path dependence, a influência das reformas institucionais de 1992-1996 foi possivelmente maior do que a dependência em relação ao passado soviético" (Grigoryev, 2016, p. 69). Ao contrário, a natureza da economia de comando e de seus problemas em muito determinou as opções e o ritmo das mudanças - as condições diferentes do processo chinês definiram uma transição distinta, por exemplo. Em segundo lugar, como avaliado na seção anterior, o PC da URSS perdeu controle da transição, consequência das contradições abertas pelo processo de Glasnost e da irreversibilidade dos avanços democráticos. Mais do que isso, a nomeklatura, assim que possível, embarca no processo espontâneo de privatização, primeiro passo na "reforma desde cima" - a chamada "privatização pela nomeklatura" (Cohen, 2011, p. 137). Em terceiro lugar, a situação geral da economia, na descrição de Brown (2006, p. 335) - já não mais uma economia de comando, ainda não uma economia de mercado -, pressiona a direção política para decisões rápidas, em um contexto no qual eleições democráticas estavam consolidadas. Em quarto lugar, a 
enorme pressão em favor de reformas de mercado exercida por instituições internacionais, como o Banco Mundial, o FMI e a OCDE, por economistas ligados a importantes universidades dos Estados Unidos, ao lado do aparente sucesso inicial de reformas deslanchadas na Polônia, cria um clima intelectual favorável a reformas fortemente pró-mercado ${ }^{19}$. Finalmente, a inexistência de alternativas democráticas e socialistas nos debates: a discussão se limitou a qual economia de mercado deveria ser implementada (Brown, 2006, p. 334) ${ }^{20}$.

As propostas de "terapia de choque" não são homogêneas. Uma das ideias mais importantes, nos textos de Fischer e Gelb (1991) e Lipton e Sachs (1992), é a programação da sequência das reformas (estabilização

19 Entre textos importantes para a criação do clima intelectual do início dos anos 1990, destacam-se Fischer e Gelb (1991) e Lipton e Sachs $(1990,1992)$.

20 Digna de nota é a ausência de alternativas à esquerda nesses debates. Ao contrário de expectativas de Rosdolsky (1959) e Mandel (1989), não houve um esboço relevante de alternativas que impulsionassem em direção à democracia socialista e a formas autogestionárias de propriedade coletiva. A limitação da discussão das reformas entre preservação do statu quo ou reformas de mercado coloca em questão a própria avaliação de Trotsky (1937). Rosdolsky (1959, p. 224, 235), em função da longa sobrevivência do modelo stalinista, argumentou que era necessária uma revisão da formulação de Trotsky, que seria válida para os anos 1930, mas inadequada para o final dos anos 1950. A partir de 1991, após a bancarrota da economia de comando e sua transição para uma economia de mercado, uma nova reavaliação é necessária: a forma com termina a economia de comando esclarece como o modelo stalinista foi um poderoso eliminador de qualquer possibilidade de desenvolvimento em direção à auto-organização de trabalhadores e da população em geral. Esse final da economia de comando cobra mais uma reavaliação da natureza transitória do sistema econômico sob Stalin - o caráter híbrido, transitório, nem capitalista nem socialista sugerido por Trotsky, com seu desenvolvimento bloqueado pela burocracia, precisa ser rediscutido. $\mathrm{O}$ arranjo político e econômico materializado no modelo stalinista não poderia ter essa natureza transitória, pois, utilizando o terror como arma política, eliminou sistemática e violentamente qualquer possibilidade de desenvolvimento em direção a uma sociedade mais avançada do que a capitalista.A revolução de outubro de 1917 iniciou a construção de uma ordem não capitalista, mas, em especial após 1929, deixou de apontar para uma sociedade mais avançada. Talvez a natureza dual da caracterização da sociedade e da economia pós-1917 na análise de Trotsky tenha desaparecido com a emergência do modelo stalinista - e do regime totalitário no sentido de Hanna Arendt. Isso pode ser visto agora, pois o resultado do processo, com a transição para uma economia de mercado, deve ser incluído na avaliação da economia e da sociedade sob Stalin: um sistema econômico singular, que organiza a transição de uma forma de capitalismo (herdada dos czares) para outra forma de capitalismo (dominada pela nomeklatura, um produto da economia de comando), de capitalismo periférico, como será discutido adiante. 
macroeconômica, retirada de subsídios, liberalização de preços, introdução de competição na economia, abertura ao comércio exterior, reforma do sistema monetário e financeiro, introdução de proteção ao desemprego, mudanças no gerenciamento de empresas estatais e privatização). Um dos debates sobre os problemas derivados da terapia de choque relaciona-se com a existência ou não dessa sequência de reformas. Além dessa sequência, a natureza, a abrangência e o estilo da privatização eram tema de controvérsia - Sachs (2012), por exemplo, afirma que considerava não ser tão urgente a privatização das empresas dos setores de recursos naturais ${ }^{21}$.

Murrell (1995) apresenta um balanço geral das propostas apresentadas a partir do meio acadêmico dos Estados Unidos. Há um debate importante aqui sobre a natureza de uma economia de mercado, sobre o papel de instituições e da sua construção: boa parte das propostas relacionadas às diversas versões da terapia de choque podem ser associadas a visões bastante simplistas sobre a construção de instituições de mercado. Nesse sentido, a transição da economia de comando para a economia de mercado contém importantes lições teóricas, que devem discutidas cuidadosamente.

Em termos da mudança da estrutura de propriedade (a mudança no bloco 2 do esquema de Kornai), duas instruções do governo Yeltsin inauguram as privatizações em massa na Rússia, através da privatização por vouchers: em 14 de agosto de 1992 publica-se uma portaria sobre "a introdução do sistema de privatização através de vouchers", completada por outra portaria de 14 de outubro de 1992, sobre "a expansão do sistema de privatização através de vouchers" (Augustynowicz, 2014, p. 137). Esse processo, segundo Graber, "transferiu milhares de empresas em sua maioria para gerentes e empregados dessas unidades" (Graber, 2006, p. 407).

Os dados apresentados por Augustynowicz (2014, p. 138) descrevem a intensidade do processo de mudança estrutural: entre 1991 e 1992 cerca de 36.800 empresas teriam sido privatizadas, enquanto em 1993 foram privatizadas 42.900 empresas e em 1994 cerca de 21.900 empresas. Em termos de distribuição de emprego, enquanto em 1990 o setor es-

21 Sachs (2012) chega a sugerir a existência de duas interpretações da "terapia de choque", uma delas "neoliberal", com a qual ele não se identificaria. 
tatal respondia por 82,6\% dos empregos, em 1995 essa participação caiu para 42,1\% (Augustynowicz, 2014, p. 140).

A "privatização para a nomeklatura" em sua fase mais aguda: Cohen (2011, p. 156) associa essa onda massiva de privatizações a um processo de acumulação primitiva de capital, com implicações sobre a natureza da democracia que se estabelecia na Rússia. Nesse processo inicia-se um conjunto de restrições e limitações ao processo democrático, que terminam definindo o que Perry Anderson (2007) avalia ser uma "democracia gerenciada".

A próxima rodada de privatizações é também determinada politicamente: o esquema de "empréstimos-em-troca-de-ações". Segundo Graber, durante 1995 e 1997 esse esquema "possibilitou que poderosos oligarcas adquirissem do Estado, por preços baixos, através de leilões fraudados, algumas das mais valiosas empresas russas, incluindo, entre outras, a Yukos, a Sibneft e a Sidanco" (Graber, 2006, p. 407)22.

Com essa segunda onda de privatizações, completa-se a mudança da estrutura de propriedade das empresas na Rússia. Augustynowicz calcula que, entre 1995 e 1998, cerca de 19.800 empresas foram privatizadas e que, em 2000, o setor estatal respondia por $37,8 \%$ dos empregos, e o setor privado em sentido estrito empregava $46,1 \%$ do total (Augustynowicz, 2014, p. 134, 140). O processo de privatização não contribuiu para a recomposição das finanças públicas, dado o valor irrisório recebido: Maddison (2001, p. 157) compara o valor total das privatizações no Brasil (US\$ 66,7 bilhões) com o valor total recebido pelas privatizações na Rússia (US $\$ 7,5$ bilhões).

Os resultados da terapia de choque como mecanismo de transição podem ser observados no Gráfico 2, a partir de dados do Banco Mundial. Ao invés de uma previsão de Lipton e Sachs - "aumentos no nível de vida médio dentro de poucos anos” (Lipton; Sachs, 1992, p. 213-214) ${ }^{23}-$,

22 Guriev e Rachinsky (2005, p. 138) descrevem esse esquema, associando-o à consolidação do apoio de banqueiros à reeleição de Yeltsin em 1996. Sachs descreve esse esquema como "uma ampla e corrupta transferência de empresas de recursos naturais para apoiadores do governo" durante a reeleição deYeltsin, no qual "dezenas de bilhões de dólares em ativos de recursos naturais foram cedidos e centenas de milhões de dólares coletados em troca como contribuições de campanha" (Sachs, 2012, p. 13).

23 Esse tipo de previsão era comum no final dos anos 1980 e início dos anos 1990. A passagem completa de Lipton e Sachs contém alguns senões: "O velho sistema de 
o hiato com os Estados Unidos se amplia, alcançando o mesmo nível da economia brasileira em 1998 - Um primeiro indício da transformação da Rússia em mais uma economia periférica? Em termos de PIB, houve um recuo de 42,5\% entre 1990 e $1998^{24}$ : uma catástrofe econômica. Cohen (2011, p. 144) comenta a repetição de métodos de "modernização através de catástrofe" na história russa, relacionando-os com as "revoluções desde cima" de Pedro, o Grande, até Stalin: a terapia de choque de Yeltsin teria repetido esse método.

Gráfico 2 - Hiato do PIB per capita da Rússia e do Brasil em relação ao PIB per capita dos Estados Unidos (PPP, constant 2011 international \$), 1990-2014

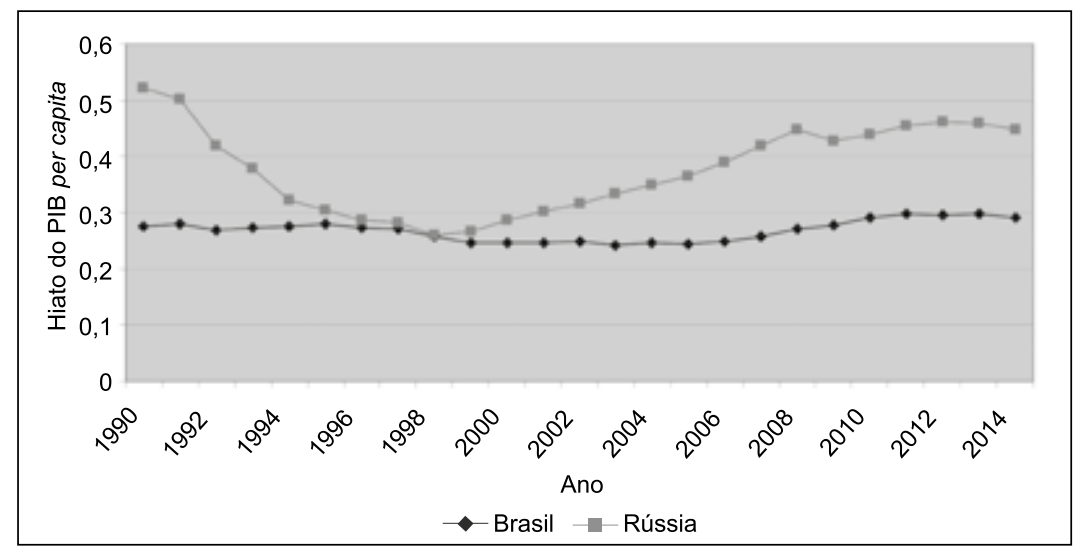

Fonte:World Bank (2016a), elaboração própria.

Economistas envolvidos na discussão da terapia de choque avaliam criticamente o resultado final - o estado da economia entre 1997-1998. Fischer (1998) elogia os passos dados até então (desenvolvimentos políticos, construção de instituições de mercado e avanços na formulação de políticas públicas), mas afirma que "a maior restrição para a Rússia

comando foi tão ineficiente e destrutivo da qualidade da vida econômica, que existe uma margem enorme para aumentos no nível de vida médio dentro de poucos anos, especialmente caso recursos sejam deslocados do complexo militar-industrial para outros setores" (Lipton; Sachs, 1992, p. 213-214). Para um comentário mais geral sobre o tom das previsões apresentadas no início dos anos 1990, ver Popov (2016, p. 88-89, 94, nota 12).

24 Em dólares internacionais de 2011, critério PPP (World Bank, 2016b). 
alcançar taxas satisfatórias de crescimento é o fato de as reformas estruturais não terem sido suficientemente profundas", sugerindo a necessidade de uma "mais rápida e mais transparente privatização de empresas estatais", "reestruturação da precificação dos monopólios naturais", "reforma urbana e imobiliária", "desenvolvimento dos mercados de capitais", "continuidade da abertura da economia para o investimento e o comércio estrangeiro”. Sachs (2012) explicitamente se distancia do processo de privatização implementado. A crítica mais forte de Sachs (2012, ver tópico "The lack of Western assistance") ao conjunto do processo foi a falta de apoio da comunidade internacional - do G7 em particular (Hanson, 2003, p. 238). Aslund (2014) afirma que o maior problema foi o fracasso em alcançar a estabilização financeira.

Qual o resultado final do processo de transição?

O custo social do modelo de transição escolhido é discutido em diversos textos - o próprio Banco Mundial se pergunta: "Is transition a killer?” (World Bank, 1996, box 8.1). Para uma síntese das avaliações, ver Popov e Dutkiewicz, que concluem ter sido essa transição "a maior crise econômica artificialmente criada da história da humanidade" (Popov; Dutkiewicz, 2016, p. 42).

Um balanço geral da transição é apresentado em sete fatos estilizados por Campos e Coricelli:

1) o produto caiu;

2) o capital encolheu;

3) o trabalho se moveu ${ }^{25}$;

4) o comércio foi reorientado (em direção às economias industrializados do Ocidente);

5) mudança estrutural - o valor adicionado pela indústria caiu rapidamente;

6) as instituições entraram em colapso;

7) os custos foram altos.

Esse último fato estilizado é desdobrado, pois, segundo os autores, "uma das surpresas da transição foi o aparecimento de custos inesperados.

25 Saíram da Rússia 2 milhões de emigrantes em bom nível educacional (Grigoryev, 2016, p. 77). 
Eram esperados o aumento do desemprego e o da desigualdade de renda. Não eram esperados a subida das taxas de mortalidade e o declínio nas taxas de escolarização" (Campos; Coricelli, 2002, p. 817).

\section{Uma nova variedade de capitalismo periférico}

Qual o resultado final das terapias de choque implementadas como transição para uma economia de mercado? Para Shleifer e Treisman (2005, p. 152), um "país normal”, um país de renda média, com todos os problemas de países em um nível de desenvolvimento similar (corrupção, restrições e problemas na vida democrática, concentração industrial, peso do Estado na economia) - Argentina, México, Malásia, Croácia e Brasil, além da Coreia do Sul pré-catch up, são mencionados. Esse final do processo de transição está também na avaliação de Popov e Dutkiewicz, para os quais,

durante a Perestroika de Gorbachev no final dos anos 1980, a URSS buscou se transformar em um dos países democráticos mais ricos do mundo. Porém, ao invés de alcançar esse status, a Rússia experimentou uma recessão transformacional de magnitude sem precedentes e na década seguinte caiu para o nível de um país em desenvolvimento comum. (Popov; Dutkiewicz, 2016, p. 50)

Ou seja, o final do processo de transição transforma a Rússia em mais um país na periferia do capitalismo ${ }^{26}$.

Um capitalismo periférico com uma alta concentração de propriedade, com forte peso dos "oligarcas" (Cohen, 2011, p. 205). Guriev e Rachinsky (2005, p. 137) sistematizam a concentração industrial em 32 setores industriais da economia russa - uma elevada concentração, certamente uma herança da economia de comando (19 setores com CR $4>$ 40\%, 12 setores com CR $4<40 \%$ ), com os "oligarcas" controlando mais

26 A partir de dados para a década de 2010, de patentes depositadas no USPTO e de artigos científicos indexados no ISI, a Rússia localizar-se-ia na periferia, em um grupo do qual participam o Brasil, o México, a África do Sul, a China e a Índia, dentre outros países (ver Ribeiro; Albuquerque, 2016, p. 175, 178). 
de $50 \%$ das vendas em 8 setores (setores em geral relacionados aos recursos naturais - extração e processamento - e automóveis).

Um capitalismo periférico com severos problemas na constituição de suas instituições democráticas, limites à democracia, que são avaliadas como consequência da natureza do processo de privatização. Cohen (2011, p. 153,204) discute a relação entre desdemocratização e estilo de privatização, assim como aponta a propriedade privatizada como barreira a democratização e modernização. Perry Anderson (2007) e Csillag e Szelényi (2015) apresentam avaliações abrangentes da natureza política do regime que se consolida após a transição: "democracia gerenciada" ou “democracia não liberal”. Shleifer e Treisman (2005, p. 163-171) não negam esses problemas gerais na construção da democracia, apenas afirmam que são problemas típicos de países do mesmo nível de desenvolvimento.

Através dos Gráficos 1 e 2, pode-se inferir que o hiato da renda per capita da Rússia em relação ao existente na era dos czares ainda não foi superado - a economia da Rússia, segundo o Gráfico 2, não conseguiu retornar ao nível de 1991, que foi inferior ao nível de 1913, segundo o Gráfico 1.

Porém, esse novo país capitalista periférico tem uma posição geopolítica singular, em função do contexto geopolítico precedente. Buzan (2004, p. 86) sugere que a ordem mundial que sucede a bipolaridade da Guerra Fria pode ser caracterizada como estrutura de poder baseada em um superpoder (Estados Unidos) e quatro poderes globais (Rússia, China, Japão e Europa). Dessa forma, mesmo em uma posição econômica na periferia do capitalismo, a Rússia preserva uma força estratégica em função da história do século XX - e do estoque de armas nucleares construído na era anterior: uma importante peculiaridade de uma variedade de capitalismo.

A crise de 1998 pode ser um sinal da integração da Rússia na economia capitalista global, na medida em que ficou exposta ao contágio da crise na Ásia, em 1997 (Panitch; Gindin, 2012, p. 262-263). Em termos mais gerais, dentro da lógica de formação de um capitalismo global, essa integração da Rússia, por sua vez, é resultado de um conjunto de "ajustamentos estruturais" implementados entre 1980 e 1997, que ampliam a "mobilidade global do capital" (Panitch; Gindin, 2012, p. 248). Esse novo cenário, por sua vez, estabelece uma reestruturação 
do Estado nos Estados Unidos, para dar conta de uma nova tarefa: o gerenciamento de crises no planeta, como uma espécie de "bombeiro-chefe" (Panitch; Gindin, 2012, p. 247-248).

Expressão dessa integração é a busca da economia mundial por recursos naturais da Rússia. Esse padrão de integração manifesta-se em um país periférico dependente da exploração de recursos naturais, pois o crescimento econômico após 1999 (ver Gráfico 2) foi basicamente impulsionado pela valorização das commodities decorrentes do crescimento da China, do petróleo em especial (Grigoryev, 2016, p. 72-75). Popov e Dutkiewicz ressaltam que após a transição a "Rússia se tornou uma típica economia baseada em recursos naturais" e "genuinamente parece um país em desenvolvimento 'normal' com ricas reservas de recursos naturais” (Popov; Dutkiewicz, 2016, p. 47-49).

Essa forma de integração da economia russa na reestruturação do capitalismo global, descrito em Panitch e Gindin (2012), é expressão de uma combinação de duas dinâmicas bem definidas: por um lado, a operação das forças que reestruturam a economia global - Estados nacionais, empresas transnacionais, instituições como o Banco Mundial e o FMI - e, por outro, a Rússia passando por um quadro de relativa desarticulação em função da transição implementada nas condições discutidas na seção anterior. O resultado é a existência de pouco espaço no plano internacional e pouca força no plano interno, para conquistar uma inserção mais ativa na economia internacional - por isso um país periférico dependente da exploração de recursos naturais.

Essa característica não é nova na economia da ex-URSS ou da Rússia, pois, como discutido na seção 1 , no período de maior integração da URSS na economia mundial, a exportação de petróleo foi o elemento de integração mais importante (Nove, 1992, p. 391-392). Hanson define que a economia russa se caracterizaria pela "falta de competitividade fora do setor de recursos naturais" (Hanson, 2007, p. 889) ${ }^{27}$. Certamente aqui há uma característica atual que remonta à economia de comando, que a transição implementada não conseguiu transformar. A integração da Rússia na economia global pode ser avaliada pelo impacto da crise

27 Anderson chega a especular que “a Rússia hoje se parece mais com uma Arábia Saudita com foguetes" (Anderson, 2007,p. 21) - uma avaliação que combina o peso do petróleo na economia com a existência de mísseis estocados desde o passado. 
de 2007-2008 sobre a economia (ver Gráfico 2, com a ampliação do hiato após 2008) e pelo impacto da queda do preço do petróleo a partir de 2012 (ver Gráfico 2, com um outro ponto de inflexão a partir de 2012).

Se essa forma de integração na economia global é uma característica nova e persistente, uma avaliação da variedade de capitalismo em implementação na Rússia hoje deve incorporar a análise das mudanças implementadas desde 1991: o sistema econômico em transição está longe de ser homogêneo desde então. Grigoryev, por exemplo, sintetiza ao menos três fases distintas desde o fim da URSS: fase Yeltsin (19921999); fase "modelo de crescimento baseado no petróleo" (2001-2008); fase "desaceleração do crescimento e crise do modelo baseado no petróleo" (2009-2014) (Grigoryev, 2016, p. 68-77).

Há mudanças estruturais nesse período?

A crise de 1998 tem um efeito importante na demarcação de períodos: Grigoryev (2016, p. 72) avalia que o período de "reformas liberais" teria se encerrado com Primakov como primeiro-ministro, entre setembro de 1998 e maio de 1999. Nesse ponto, já estaria definido o tipo de capitalismo russo, determinado pelas "instituições básicas, especialmente na área da propriedade [...], criadas nos quatro ou cinco anos de reformas" (Grigoryev, 2016, p. 72).A superação da crise de 1998 deveu-se, segundo Grigoryev (2016, p. 72-73), à desvalorização do rublo, à gradual elevação dos preços do petróleo, às reservas de capacidade produtiva e de trabalho e a uma reestruturação do sistema de impostos. A partir de 2004, há uma certa recuperação da capacidade de ação do Estado (Grigoryev, 2016, p. 73).

Hanson (2007, p. 875-879) avalia que houve, a partir de 2003, mudanças profundas a ponto de caracterizar "uma volta ao estatismo", começando pelo crescimento da intervenção estatal na indústria de petróleo, com o takeover da empresa Yukos pela estatal Rosneft, mas segundo Hanson o crescimento da participação do Estado não teria se limitado à indústria petroleira. Nessa linha também, a revista The Economist (2012) sugere que a Rússia poderia ser caracterizada como um tipo de capitalismo dirigido pelo Estado (ao lado da China e do Brasil) - o dado desse special report é a participação de empresas controladas pelo Estado no total da capitalização de mercado em bolsas de valores ${ }^{28}$.

28 Duas outras posições podem ser mencionadas. Em primeiro lugar,Aslund (2014, p. 105) 
Esse tema é controverso: os dados apresentados por Augustynowicz (2014, p. 140) indicam o aumento da participação do setor privado entre 2000 e 2010: de 46,1\% do total do emprego em 2000 cresce para $54,1 \%$ em 2005 e para 58,6\% em 2010. Estrin et al. (2009), com dados do EBRD relativos à participação no $\mathrm{PIB}$, mostram que o pico da participação estabeleceu-se em 1997 - 70\% -, participação mantida até 2004. Em 2005 e 2006 essa participação cai para 65\% do PIB.

A OECD (2010, p. 133-136), por sua vez, avalia que o setor estatal ainda é muito grande na economia russa, sugerindo novas rodadas de privatização. Em 2010 houve um novo plano de privatização, com a meta de privatizar mais 1.500 empresas, plano que excluía empresas do setor de petróleo e de setores definidos como estratégicos (OECD, 2014, p. 62). Esses setores foram definidos por lei de 2008, nos quais seriam implementadas restrições ao capital estrangeiro (OECD, 2014, p. 149): setores com monopólio natural (algumas exceções, como eletricidade) e 42 setores relacionados à defesa, alta tecnologia, e setores com propósitos duais (civis e militares), como aeroespacial e atividades nucleares.

Uma avaliação da natureza do capitalismo na Rússia hoje deve incorporar as mudanças pós-2000. Uma interpretação possível é considerar o ano de 1998 como uma referência, na medida em que o impacto completo do estilo de transição se fez sentir (o maior hiato em termos de PIB per capita em relação aos Estados Unidos, ver Gráficos 1 e 2), ao mesmo tempo em que um efeito da integração ao capitalismo global é sentido através da crise de 1998.

Esses dois fenômenos, aliados à percepção da transformação da Rússia em um país mais dependente de seus recursos naturais, detonam processos políticos internos, buscando uma ajustamento da posição da Rússia no novo cenário internacional.A busca de maior controle estatal sobre setores agora claramente estratégicos passa a ser implementada. Consciente ou inconscientemente, a montagem de um Estado com alguma capacidade de liderar um processo de desenvolvimento é tentado.

considera que Putin começou com reformas liberais (2000-2004), passou para um “capitalismo de Estado" entre 2004 e 2008, moveu-se em direção a um capitalismo de compadrio (crony capitalism) entre 2008 e 2012, e após 2012 oscilou entre esses dois tipos (capitalismo de Estado e capitalismo de compadrio). Em segundo lugar, Djankov $(2015$, p. 3) identifica na era Putin um movimento do capitalismo de compadrio para um capitalismo estatal. 
Portanto, pode-se identificar uma transformação estrutural a partir de 1998, com a retomada de um papel mais atuante para o Estado na Rússia - esse novo papel do Estado definiria a emergência de uma nova variedade de capitalismo.

Assim, embora o setor privado seja preponderante na economia russa, o controle do Estado (direto ou indireto) sobre setores estratégicos multiplica o peso geral do setor estatal. Esses elementos combinados delimitam o tipo de capitalismo existente na Rússia. Não é difícil contrastar esse tipo com outros países em transição para economias de mercado (como a China) e com outros países periféricos (como o Brasil e o México), e com outros países ricos em recursos naturais (como a Arábia Saudita e o Irã $)^{29}$.

\section{Comentários finais}

A história econômica da Rússia desde 1913 é plena de lições para estudantes de sistemas econômicos comparados. Certamente, cada passo decisivo entre os sete diferentes sistemas econômicos que existiram entre 1913 e 2016 é pleno de opções abertas e não há um determinismo implacável operando.

Porém, em uma análise ex post do conjunto do processo, é possível acompanhar uma trajetória bem definida, na qual há um encadeamento de estruturas e acontecimentos que define limites de escolhas e opções ao longo desse percurso histórico. Assim, a variedade de capitalismo da Rússia contemporânea - periférica, liderada pelo Estado, oligárquica e com uma democracia limitada - é resultado da transição baseada em terapias de choque. Por sua vez, a escolha do tipo de transição foi condicionada pela natureza da crise da economia de comando na década de 1980. Essa crise foi o resultado de contradições internas da economia de comando construída entre 1929 e 1953. Essa economia de comando gerou um limitado processo de catch up, industrializou a

29 Essa discussão da variedade de capitalismo específica à Rússia atual pode ser realizada combinando abordagens de Coates (2000) e Freeman (1995). Nessa combinação, o papel do Estado é importante para delimitar diferentes tipos de capitalismo, em especial das variedades resultantes de diferentes transições de diferentes formas de economias de comando (China e Rússia), como sugere King e Szelényi (2005). 
economia com grande custo humano, gerando uma economia relativamente atrasada com fortes capacidades militares, que indica os limites estruturais para a transição e para o resultado do processo. Por isso, não é acidental que a Rússia tenha transitado de uma economia de comando tecnologicamente atrasada para uma variedade de capitalismo periférico e com forte dependência de recursos naturais.

\section{Referências bibliográficas}

ALBUQUERQUE, E. Lições da tragédia: limites e contradições do progresso tecnológico na União Soviética. In: PAULA, J.A. (org.). Adeus ao desenvolvimento: a opção do governo Lula. Belo Horizonte: Autêntica, 2005, p. 253-273.

ANDERSON, Perry. Russia's managed democracy. London Review of Books, v. 29, n. 2, 2007. Disponível em <http://www.lrb.co.uk/v29/n02/perry-anderson/russias-managed-democracy $>$. Acesso em 21/3/2016.

ARENDT, Hanna. The origins of totalitarianism. Orlando: Harcourt, 1985 (1968).

ASLUND, Anders. The arduous transition to a market economy. In: ASLUND, Anders; DJANKOV, Simeon. The great rebirth: lessons from the victory of capitalism over communism. Washington: Peterson Institute for International Economics, 2014, p. 89-112. Disponível em <https://piie.com/publications/chapters_ preview/6970/05iie6970.pdf>. Acesso em 12/4/2016.

AUGUSTYNOWICZ, Pawel. State-owned enterprises in Russia - the origin, importance and principles of operation. In:VOSZKA, É.; KISS, G. D. (orgs.). Crisis management and the changing role of the State. Szeged: University of Szeged Doctoral School in Economics, 2014, p. 133-145.

BROWN,Archie.The Gorbachev era. In: SUNY, Richard Grigor (org.). The Cambridge history of Russia.V. III: The twentieth century. Cambridge: Cambridge University Press, 2006, p. 316-351.

BUZAN, B. The United States and the great powers: world politics in the twentieth-first century. Cambridge: Polity Press, 2004.

CAMPOS, Nauro; CORICELLI, Fabrizio. Growth in transition: what we know, what we don't, and what we should. Journal of Economic Literature, v. XL, p. 793-836, 2002.

COATES, D. Models of capitalism. Cambridge: Polity Press, 2000.

COHEN, Stephen F. Soviet fates and lost alternatives: from Stalinism to the new Cold War (with a new epilogue). New York: Columbia University Press, 2011.

CONQUEST, Robert. The harvest of sorrow: Soviet collectivization and the terror-famine. New York: Oxford University Press, 1986.

CSILLAG, Tamás; SZELÉNYI, I. Drifting from liberal democracy: traditionalist/neoconservative ideology of managed illiberal democratic capitalism in post-communist Europe. Intersections. East European Journal of Society and Politics, v. 1, n. 1, p. 18-48, 2015. 
Disponível em <http://intersections.tk.mta.hu/index.php/intersections/article/ view/28/2>.

DAVIES, R. W. Soviet economy development from Lenin to Khruschev. Cambridge: Cambridge University Press, 1998.

DJANKOV, Simeon. Russia's economy under Putin: from crony capitalism to State capitalism. Policy Brief. Washington, Peterson Institute for International Economics, n. 15-18, 2015.

DEUTSCHER, Isaac. Trotski - o profeta armado. Rio de Janeiro: Civilização Brasileira, 1984 (1954).

ELSON, D. Market socialism or socialization of the market. New Left Review, n. 172, p. 3-44, Nov.-Dec. 1988.

ESTRIN, Saul et al.The effects of privatization and ownership in transition economies. Journal of Economic Literature, v. XLVII, n. 3, p. 699-728, 2009.

FISCHER, S. The Russian economy at the start of 1998. International Monetary Fund, 1998. Disponível em < https://www.imf.org/external/np/speeches/1998/010998. htm>. Acesso em 12/4/2016.

FISCHER, Stanley; GELB, Alan. The process of socialist economic transformation. Journal of Economic Perspectives, v. 5, n. 4, p. 91-105, 1991.

FREEMAN, C.The "National System of Innovation" in historical perspective. Cambridge Journal of Economics, v. 19, n. 1, p. 5-24, 1995.

FREEMAN, C.; LOUÇÃ, F. As time goes by: from the industrial revolutions and to the information revolution. Oxford: Oxford University, 2001.

GATRELL, Peter. Economic and demographic change: Russia's age of economic extremes. In: SUNY, Richard Grigor (org.). The Cambridge history of Russia.V. III: The twentieth century. Cambridge: Cambridge University Press, 2006, p. 383-410.

GERSCHENKRON, A. Russia: patterns and problems of economic development, 1861-1958. Economic backwardness in historical perspective: a book of essays. Cambidge: The Belknap Press of Harvard University, 1962 (1960), p. 119-151.

GRABER, Peter. Economic and demographic change: Russia's age of economic extremes. In: SUNY, Richard Grigor (org.). The Cambridge history of Russia.V. III: The twentieth century. Cambridge: Cambridge University Press, 2006, p. 383-410.

GRAHAM, L. R. Science in Russia and the Soviet Union: a short history. Cambridge: Cambridge University Press, 1993.

GREGORY, P.; HARRISON, M. Allocation under dictatorship: research in Stalin's archives. Journal of Economic Literature, v. XLIII, p. 721-761, 2005.

GRIGORYEV,Leonid.Transformation: for the people or for the elite?. In:DUTKIEWICZ, Piotr;SAKWA, Richard; KULIKOV,Vladimir (orgs.). The social history of post-communist Russia. London/New York: Routledge, 2016, p. 58-80.

GURIEV, Sergei; RACHINSKY, Andrei. The role of oligarchs in Russian capitalism. Journal of Economic Perspectives, v. 19, n. 1, p. 131-150, 2005.

HANSON, Philip. The rise and fall of the Soviet economy. London/New York: Routledge, 2003. 
HANSON, Philip.The Russian economic puzzle: going forwards, backwards or sideways. International Affairs, v. 83, n. 5, p. 869-889, 2007.

HANSON, Philip; PAVITT, Keith. The comparative economics of research, development and innovation in East and West: a survey. London: Harwood Academic Publishers, 1987.

HANSON, Stephen. The Brezhnev era. In: SUNY, Richard Grigor (org.). The Cambridge history of Russia.V. III: The twentieth century. Cambridge: Cambridge University Press, 2006, p. 292-315.

HILFERDING, R. State capitalism or totalitarian State economy?, 1940. Disponível em <www.marxists.org/arcjhive/hilferding/1940/statecapitalism>. Acesso em 4/8/2014.

HOBSBAWM, E. J. Era dos extremos: o breve século XX, 1914-1991. 2. ed. São Paulo: Companhia das Letras, 1995 (1994).

KING, L. P.; SZELÉNYI, I. Post-communist economic systems. In: SMELSER, N.; SWEDBERG, R. (orgs.). The handbook of economic sociology. 2. ed. Princeton/New York: Princeton University Press/Russel Sage Foundation, 2005, p. 205-229.

KORNAI, J. The socialist system: the political economy of communism. Princeton: Princeton University Press, 1992.

KORNAI, J. What the change of system from socialism to capitalism does and does not mean. Journal of Economic Perspectives, v. 14, n. 1, p. 27-42, 2000.

LANGE, Oskar. O papel do planejamento numa sociedade socialista. In: POMERANZ, Lenina (org.). Oskar Lange. São Paulo: Ática, 1981 (1957), p. 121-136 (Grandes Cientistas Sociais, 18).

LEWIN, Moshe. Russian peasants and Soviet power: a study of collectivization. New York: W.W. Norton \& Company Inc., 1968.

LEWIN, Moshe. Political undercurrents in soviet economic debates: from Bukharin to the modern reformers. Princeton: Princeton University Press, 1974.

LIEFERT, William M.; LIEFERT, Olga. Russian agriculture during transition: performance, global impact and outlook. Applied Economic Perspectives and Policy, v. 34, n. 1, p. 37-75, 2012.

LINDEN, Marcel van der. Western marxism and the Soviet Union: a survey of theories and debates since 1917. Leiden/Boston: Brill, 2007.

LIPTON, David; SACHS, Jeffrey. Creating a market economy in Eastern Europe: the case of Poland. Brookings Papers on Economic Activity, 1, p. 75-133, 1990.

LIPTON, David; SACHS, Jeffrey. Prospects for Russia's economic reforms. Brookings Papers on Economic Activity, 2, p. 213-283, 1992.

LUXEMBUR GO, Rosa. A revolução russa. In: LOUREIRO, I. (org.). Rosa Luxemburgo: textos escolhidos.V. II. São Paulo: Editora UNESP, 2011 (1918), p. 175-212.

MADDISON, Angus. The world economy: a millennial perspective. Paris: OECD, 2001.

MADDISON,Angus. Historical statistics of the world economy -1-2008 AD. Groningen Growth and Development Centre, 2010. Disponível em <www.ggdc.net/maddison/ Historical_Statistics/horizontal-file_02-2010.xls>. Acesso em 30/6/2016.

MANDEL, Ernest. In defense of socialist planning. New Left Review, n. 159, p. 4-37, Sep.-Oct. 1986. 
MANDEL, Ernest. Além da Perestroika. São Paulo: Busca Vida, 1989.

MCFAUL, Michael. The Russian Federation. In: SUNY, Richard Grigor (org.). The Cambridge history of Russia V. III: The twentieth century. Cambridge: Cambridge University Press, 2006, p. 352-381.

MURRELL, Peter. The transition according to Cambridge, Mass. Journal of Economic Literature, v. 33, n. 1, p. 164-178, 1995.

NAUGHTON, B. Growing out of the plan: Chinese economic reform, 1978-1993. Cambridge: Cambridge University Press, 1995.

NOVE, Alec. The economics of feasible socialism. London: George Allen \& Unwin, 1983.

NOVE, Alec. An economic history of the USSR - 1917-1991. 3. ed. London: Penguin, 1992.

OECD. OECD Economic Surveys: Russian Federation 2009, OECD Publishing, 2010. Disponível em <DOI:10.1787/eco_surveys-rus-2009-en>.Acesso em 25/3/2016.

OECD. OECD Economic Surveys: Russian Federation 2013, OECD Publishing, 2014. Disponível em <DOI:10.1787/eco_surveys-rus-2013-en>.Acesso em 25/3/2016.

OHKAWA, K; KOHAMA, H. Lectures on developing economics: Japan's experience and its relevance. Tokyo: University of Tokyo, 1989.

PANITCH, L.; GINDIN, S. The making of global capitalism: the political economy of American Empire. London:Verso, 2012.

POPOV, Vladimir. Puzzles of public opinion: popular support for the transition to capitalism. In:DUTKIEWICZ, Piotr; SAKWA, Richard; KULIKOV,Vladimir (orgs.). The social history of post-communist Russia. London/New York: Routledge, 2016, p. 81-94.

POPOV,Vladimir; DUTKIEWICZ, Piotr. A time of transition: changes in reality and perceptions. In: DUTKIEWICZ, Piotr; SAKWA, Richard; KULIKOV, Vladimir (orgs.). The social history of post-communist Russia. London/New York: Routledge, 2016, p. 41-57.

RIBEIRO, L.; ALBUQUERQUE, E. O papel da periferia na atual transição para uma nova fase do capitalismo: questões introdutórias nas mudanças da divisão centro-periferia. Cadernos do Desenvolvimento, v. 10, n. 17, p. 166-186, 2016.

ROSDOLSKY, R. Zur Analyse der Russischen Revolution. In:WOLTER, U. (org.). Sozialismusdebate: Historische und aktuelle Fragen des Sozialismus. Berlin:Verlag Offe \& Wolter, 1978 (1959), p. 203-236.

SACHS, Jeffrey. What I did in Russia, (2012) Disponível em <http://jeffsachs. org/2012/03/what-i-did-in-russia/>. Acesso em 19/3/2016.

SHLEIFER,Andrei;TREISMAN, Daniel. A normal country: Russia after communism. Journal of Economic Perspectives, v. 19, n. 1, p. 151-174, 2005.

SZELÉNYI, I. A theory of transitions. Modern China, v. 34, n. 1, p. 165-175, 2008.

SZELÉNYI, I.;BECKETT, K.; KING, L. P.The socialist economic system. In:SMELSER, N.; SWEDBERG, R. (orgs.). The handbook of economic sociology. Princeton: Princeton University Press, 1995, p. 234-251. 
THE ECONOMIST. The visible hand: a special report on State capitalism. 21 Jan. 2012. Disponível em <http://www.economist.com/specialreports/>. Acesso em $12 / 10 / 2015$.

TROTSKY, L. A revolução traída. São Paulo: Global, 1980 (1937).

TUCKER, R. Stalin as a revolutionary: a study in history and personality, 1879-1929. New York: W.W. Norton \& Cia., 1974.

TUCKER, R. (org.). Stalinism: essays in historical interpretation. New Brunswick/ London: Transaction Publishers, 1977.

TUCKER, R. Stalin in power: the revolution from above, 1928-1941. New York: W.W. Norton \& Cia., 1992.

WORLD Bank. World development report 1996: from plan to market. Oxford: Oxford University Press, 1996.

WORLD Bank. World development indicators, 2016a. Disponível em $<$ http://data.worldbank.org/indicator/NY.GDP.PCAP.PP.KD>. Acesso em 27/4/2016.

WORLD Bank. World development indicators, 2016b. Disponível em <http://data.worldbank.org/indicator/ NY.GDP.MKTP.PP.KD>. Acesso em 27/4/2016. 